\title{
PROFESSIONAL TRAINING OF COMPUTATIONAL LINGUISTS AT THE UNIVERSITY OF STUTTGART
}

\begin{abstract}
The paper deals with the aspects of professional training of specialists in computational linguistics by the example of the University of Stuttgart. First of all, we have attempted to define the essence of the terms "applied linguistics" and "computational linguistics" based on the views of Ukrainian and foreign scholars. We have found out that there is an obvious inconsistency in using these terms as Ukrainian scholars view it as a science related to practical application of linguistic achievements with the use of the latest technologies, whereas abroad they believe that computational linguistics is aimed at developing strategies for researches on natural languages. However, applied linguistics is related to language teaching methodology. We have concluded that German scholars view computational linguistics as a cognitive science that attempts to most successfully apply the achievements of linguistics in practice. Based on the view, German universities develop curricula that encompass theoretical and practical aspects of computational linguistics to prepare modern specialists able to comprehend the complexity of the field and be willing to adapt to challenges of a globalized world. Consequently, we have described the peculiarities of the programmes of a Bachelor of Science in Machine Language Programming and a Master of Science in Computational Linguistics. We have defined that duration of the programmes is traditional - three and two years respectively. Their structure comprises obligatory and elective courses, including Computer Science, Mathematics and Linguistics. In addition, future specialists may develop key professional competences attending seminars and colloquiums, participating in research projects, etc. It has been indicated that the list of electives involves those subjects aimed at enhancing future specialists' skills in linguistics as well as computer science, yet they are entitled to suggest what they are interested in even if such courses are not included. We have also suggested that rather perspective are further studies on the essence of the terms "applied linguistics" and "computational linguistics" based on the research findings of scholars all over the world.

Keywords: computational linguistics, applied linguistics, professional training, computational linguist, Germany, the University of Stuttgart.

\section{INTRODUCTION}

Considering political, economic, social and cultural transformations taking place in the world, one cannot underestimate their influence on all the spheres of human lives in Ukraine, including higher education. The $21^{\text {st }}$ century is definitely characterized by the emergence of new approaches to developing higher education and those ideas that may help to solve topical educational and economical problems. They include multifaceted models of higher education institutions, top-priority of quality professional training, development of professional competencies, sustainable partnership between the global economics and the
\end{abstract}


labour market, international and social partnership in higher education. So, current integration and globalization processes alter the paradigm of Ukraine's higher education trends orienting toward humanization, humanitarization, internationalization, diversification, optimization, social partnership, etc.

Another important point is the vast popularization of the information and communication technologies (ICTs). Today it is impossible to imagine any sphere without using them. Although they penetrated our lives quite a long time ago, we can still observe how new features of this phenomenon appear and greatly affect the outcomes of any activity and, moreover, change the worldview of individuals. In this regard, it is reasonable to mention computational linguistics. Being a rather new field of scientific knowledge, it has managed to attract many followers and prove to be in-demand as a profession. Thus, millions of users all over the world sending requests to information retrieval systems (IRS), giving speech commands to their devices, performing automatic text summarization do not suspect that this became possible as a result of the development of the subject area of computational linguistics aimed at researching and developing algorithms and natural language programming.

\section{THE AIM OF THE STUDY}

Given the recognition and acceptance of German university curricula, we have attempted to study the organization of computational linguists' professional training on the example of the University of Stuttgart and outline positive aspects of this experience in the conclusions of our manuscript.

\section{THEORETICAL FRAMEWORK AND RESEARCH METHODS}

Theoretical framework of our research is based mainly on the research findings of German higher education institutions and scholars. Thus, to find out the definition of computational linguistic we first applied to official websites of German universities providing degree programmes in computational linguistics (the University of Stuttgart, the University of Heidelberg, the University of Potsdam, Ludwig Maximilians University in Munich). Consequently, we took into account the views on applied linguistics and computational linguistics by Ukrainian (O. Semotiuk, O. Selivanova) and foreign (K. Knapp, F. Königs, Naves, Spillner, H. Uszkoreit, H. Widdowson) scholars.

The peculiarities of professional training of computational linguists in detail have been analyzed based on the data provided by the University of Stuttgart.

During our study we have used such methods as analysis and synthesis, systematization and generalization, deduction and induction.

\section{RESULTS}

To begin with, we would like to present our findings on the definitions of computational linguistics and applied linguistics, as we believe it is extremely important to show different views on the subject of the science. They are rather controversial, as one may see from the information given below.

The Duden, a dictionary of the German language, defines computational linguistics (Comptuterlinguistik) as a part of modern linguistics, which uses electronic computing systems for the processing and description of linguistic problems (Duden, 2017). According to the Institute for Machine Language Processing (Institut für Maschinelle Sprachverarbeitung) at the University of Stuttgart, the machine language processing is concerned with the so-called computational linguistics and examines the language from a special angle of view. It is about making the linguistic laws explicit, in order to create computer systems on this basis that can understand and produce language (Institut für Maschinelle Sprachverarbeitung, 
2013). At Heidelberg University they believe that computational linguistics is an interdisciplinary subject, which examines how natural language can be automatically processed and interpreted by formal modeling, algorithmic methods of computer science and statistical procedures. In addition to the research-theoretical side of computational linguistics, which studies the formal (mathematical and logical) properties of natural language and its implementation in efficient algorithms, the science also has a strongly application-oriented orientation (Universität Heidelberg, 2017). At Potsdam University they state that computational linguistics is more than a science and engineering discipline. It also deals with the mathematical properties of natural and artificial languages. The focus is on the investigation of various formalisms to represent linguistic facts in a form, which is comprehensible to the computer (Universität Potsdam, 2011). At Ludwig Maximilians University in Munich, they indicate that computational linguistics is the study of the mechanical processing of natural languages. So, this is an interdisciplinary science, which is characterized, on the one hand, by an abundance of up-to-date applications in the area of speech technology, information search and data mining, through close content and methodical connections to traditional subjects such as linguistics, computer science, logic and phonetics (Ludwig-Maximilians-Universität München, 2017).

Based on the above-mentioned definitions, we believe it necessary to draw a parallel between the notions of computational and applied linguistics. In Ukraine, the study of the problem of automatic processing of the natural language mostly correlates with the subject area of applied linguistics, and the meaning of the term "applied linguistics" differs from the interpretation of the loan translation "applied linguistics" in foreign scientific literature, incuding Western European science generally. O. Semotiuk (2011) states that in Ukrainian tradition applied linguistics is understood as a branch of linguistics that applies the knowledge about language in order to solve applied tasks and optimize language functions (p. 66). O. Selivanova (2008) believes that applied linguistics is a full branch of linguistics aimed at solving practical tasks of different fields of science and technology, people's everyday life, society based on theoretical studies on language and speech (p. 641). At the same time, the term "computational linguistics" is not common and points out to the toolkit needed to achieve scientific results, whereas applied lingustics is oriented toward results.

In Europe, under applied linguistics they understand the discipline dealing with the problems of language teaching methodology, "up to now, the main part of the developments in applied linguistics has been devoted to teaching and, the teaching of languages, primarily English as a foreign language or a second language" (Naves, 2008, p. 4). According to the Handbook of Applied Linguistics, applied linguistics is a coherent activity, which theorizes through speculative and empirical inverstigations real-world problems in which language is a central issue (Davies \& Elder, 2004). The German scholar F. Königs (1983) defines applied linguistics as the science that applies theoretical achievements of linguistics in practice as well as that of other sciences that are only mediately related to language (p. 37). K. Knapp (2011) assumes that applied linguistics is a cross-disciplinary field of research and practice that deals with practical problems of language and communication, either available theories, methods and results of linguistics and related disciplines, or the development of new theories and implications of practical problems. B. Spillner (1987) indicates that applied linguistics is a linguistic discipline, which interacts interdisciplinarily with non-linguistic disciplines and mediates between theory and practice, thus participating in problem solving in all those human fields of practice in which language is involved. H. Widdowson (2000) suggested to distinguish "applied linguistics" 
and "linguistics applied" as it is important to take into account not only the achievements of linguistics but also that of psychology, anthropoly, philosophy, sociology, etc.

So, we can conclude that abroad and, in particular, in Germany, the terms "computational lingustics" and "applied linguistics" imply two different branches of linguistics. The first one is more practice-oriented and aims to conduct the processing of natural language with the use of various computer technologies. The second one is more related to humanities and generally means application of theoretical achievements of linguistics in language teaching methodology. If to compare the scope of two disciplines, we believe that applied linguistics is wider and uses practical achievements of computational linguistics as well; computational linguistics is more limited and directed at elaborating those means and techniques that can be used within other branches of general linguistics.

In our opinion, it is reasonable to use the term "computational lingustics" referring to relevant professional traning at German universities as it reflects the realia adopted in the higher education system of this country. The problem of inconsistency in the use of such terms as "computational linguistics" and "applied linguistics" in Ukrainian scientific thought remains open and requires detailed justification.

Now, we would like to analyze the organization of computational linguists' professional training by the example of the University of Stuttgart.

The Institute for Machine Language Processing (MLP) at the University of Stuttgart offers two degree programmes on computational linguistics: a Bachelor of Science in Machine Language Processing and a Master of Science in Computational Linguistics (Institut für Maschinelle Sprachverarbeitung, 2017).

The Bachelor programme is divided into 6 semesters and encompasses natural languages (German and English) as well as their computational processing. Therefore, the concepts of human and computational engineering are interrelated. The required expert knowledge is presented through an interdisciplinary approach including computer science, mathematics and linguistics. The MLP differs from similar programs that are more linguistically oriented as its linguistic and computational aspects are equally important during the study.

Its theoretical component concentrates on formal models of the complex processes of production and perception of verbal expressions. Thus, students master the basics of speech processing (experimental phonetics, grammar development, semantics, logics, statistics, parsing).Its practical conception includes the basic solutions to speech processing (automatic speech recognition and speech synthesis of spoken language, search engines, automatic translation systems, etc). The students can choose their own specializations (Linguistics, Computer Science, etc.). It must be noted that the knowledge of a programming language is not obligatory as it can be obtained during the first two semesters.

The courses are divided into obligatory and elective. As usual, obligatory courses are to be attended by every student, and elective ones allow the students to set their main points of interests in a predefined number of topics or areas. The ideal scheme for the BSc study in MLP is presented in Table 1.

It must be noted that the students are offered three elective areas so that they may slightly individualize their study. They may choose between the courses offered within each of these areas to receive the necessary number of credits to pass the respective elective area. The elective area $\mathrm{F}$ involves different courses on advanced natural language processing (12 credits are to be gained). They are Computational Morphology, Pragmatics, Advanced Speech Synthesis, Machine Language Processing in Medicine and Biology, Foundations of Signal Processing in Loudspeaker Processing, etc. 
Bachelor of Science in Machine Language Processing: the Scheme of the Study Programme

\begin{tabular}{|c|c|c|c|c|c|}
\hline Semester & Course & $\begin{array}{l}\text { Obligatory/ } \\
\text { Elective }\end{array}$ & $\begin{array}{c}\text { Lectures } \\
\text { (hours per week) }\end{array}$ & $\begin{array}{l}\text { Practical classes } \\
\text { (hours per week) }\end{array}$ & Credits \\
\hline \multirow{7}{*}{1} & Mathematics $1^{*}$ & $\mathrm{O}$ & 4 & 2 & 9 \\
\hline & $\begin{array}{l}\text { Theoretical Foundations } \\
\text { of Computer Science } 1\end{array}$ & $\mathrm{O}$ & 3 & 1 & 6 \\
\hline & \begin{tabular}{|l|} 
Programming \\
and Software Development
\end{tabular} & $\mathrm{O}$ & 4 & 2 & 9 \\
\hline & Introduction to MLP & $\mathrm{O}$ & 2 & & 3 \\
\hline & \begin{tabular}{|l|} 
Programming Course \\
\end{tabular} & $\mathrm{O}$ & & 2 & 3 \\
\hline & Total & & 13 & 7 & 30 \\
\hline & & & \multicolumn{2}{|c|}{20} & \\
\hline \multirow{6}{*}{2} & Mathematics 2* & $\mathrm{O}$ & 2,7 & 1,3 & 6 \\
\hline & $\begin{array}{l}\text { Theoretical Foundations } \\
\text { of Computer Science } 2\end{array}$ & $\mathrm{O}$ & 3 & 1 & 6 \\
\hline & Data Structures and Algorithms & $\mathrm{O}$ & 4 & 2 & 9 \\
\hline & Foundations of MLP & $\mathrm{O}$ & 4 & 2 & 9 \\
\hline & Total & & 13,7 & 6,3 & 30 \\
\hline & & & \multicolumn{2}{|c|}{20} & \\
\hline \multirow{7}{*}{3} & Foundations of Syntax & $\mathrm{O}$ & 3 & 1 & 6 \\
\hline & Parsing & $\mathrm{O}$ & 3 & 1 & 6 \\
\hline & Semantics & $\mathrm{O}$ & 3 & 1 & 6 \\
\hline & \begin{tabular}{|l|} 
Phonetics and Phonology \\
\end{tabular} & $\mathrm{O}$ & 3 & 1 & 6 \\
\hline & An elective & $\mathrm{E}$ & 3 & 1 & 6 \\
\hline & Total & & 15 & 5 & 30 \\
\hline & & & \multicolumn{2}{|c|}{20} & \\
\hline \multirow{7}{*}{4} & $\begin{array}{l}\text { Algorithm. Speech } \\
\text { Understanding }\end{array}$ & $\mathrm{O}$ & 3 & 1 & 6 \\
\hline & Speech Synthesis and Recognition & $\mathrm{O}$ & 4 & 2 & 9 \\
\hline & Statistical Language Processing & $\mathrm{O}$ & 3 & 1 & 6 \\
\hline & An elective & $\mathrm{E}$ & 2 & 1 & 6 \\
\hline & Key competences & & 2 & & 3 \\
\hline & Total & & 15 & 5 & 30 \\
\hline & & & \multicolumn{2}{|c|}{20} & \\
\hline \multirow{8}{*}{5} & Information Retrieval \& Text Mining & $\mathrm{O}$ & 3 & 1 & 6 \\
\hline & An elective $(\mathrm{F} \text { area })^{* *}$ & $\mathrm{E}$ & 3 & 1 & 6 \\
\hline & An elective $(\mathrm{F} \text { area })^{* *}$ & $\mathrm{E}$ & 3 & 1 & 6 \\
\hline & Project & & & 4 & 6 \\
\hline & Project seminar & & 2 & & 3 \\
\hline & Key competences & & 2 & & 3 \\
\hline & Total & & 13 & 7 & 30 \\
\hline & & & \multicolumn{2}{|c|}{20} & \\
\hline \multirow{6}{*}{6} & An elective (F area) & $\mathrm{E}$ & 3 & 1 & 6 \\
\hline & An elective ( $\mathrm{F}$ area) ${ }^{* *}$ & $\mathrm{E}$ & 3 & 1 & 6 \\
\hline & An elective (F area) & $\mathrm{E}$ & 3 & 1 & 6 \\
\hline & Bachelor's thesis & & \multicolumn{2}{|c|}{8} & 12 \\
\hline & & & 9 & 3 & 30 \\
\hline & & & \multicolumn{2}{|c|}{20} & \\
\hline
\end{tabular}

*The courses in Mathematics correspond to the seminars Mathematics I and II for Computer Science and Software Engineering. In these courses, the content is specifically tuned for a BSc in MLP. In addition, IML math tutorials are offered.

${ }^{* *}$ In total $12 \mathrm{CP}$ are to be gained in the elective area F and $18 \mathrm{CP}$ in the electives area E/I.

Based on the findings retrieved from http://www.ims.uni-stuttgart.de/studium/ interessierte/studiengaenge/bsc/index.en.html 
The elective area E/I contains modules from other BSc programmes such Electrical Engineering \& Information Technology and Computer Science (18 credits are to be gained). They are Fundamentals of Artificial Intelligence, Human-Computer Interaction, Computer Graphics, Databases and Information Systems, Fundamentals of Integrated Circuits, Telecommunications, Digital Signal Processing, Design of Digital Filters, etc. The third elective area contains modules from Linguistics and Philosophy (12 credits are to be gained). They are Language Change, Varieties of the German Language, Basic Principles of Practical Philosophy, Man and Technology, Language and Mind (Fundamentals of Theoretical Philosophy).

Key competences are to be passed in all Bachelor programmes offered at the University of Stuttgart. There are key competences with belong to the respective programme, namely, they comprise specific knowledge for the respective programme and interdisciplinary key competences.

Those, who would like to extend their knowledge, skills and competence in Computational Linguistics and Speech and Natural Language Processing, may proceed to a Master of Science in Computational Linguistics. The programme lasts two years and is based on natural languages such as German or English and how they can be represented and processed on the computer (Institut für Maschinelle Sprachverarbeitung, 2017).

Table 2

Master of Science in Computational Linguistics: the Scheme of the Study Programme

\begin{tabular}{|c|c|c|c|}
\hline Semester & Course & $\begin{array}{c}\text { Depth / Specialization / } \\
\text { Key Competence Course }\end{array}$ & Credits \\
\hline \multirow{5}{*}{1} & Methods in Computational Linguistics* & $\mathrm{D}$ & 9 \\
\hline & Computational Linguistics Concentration 1(Part 1) & $\mathrm{D}$ & 6 \\
\hline & Computational Linguistics Concentration 2 (Part 1) & $\mathrm{D}$ & 6 \\
\hline & Electives & $\mathrm{S}$ & 9 \\
\hline & Total & & 30 \\
\hline \multirow{6}{*}{2} & Computational Linguistics Concentration 1 (Part 2) & $\mathrm{D}$ & 6 \\
\hline & Computational Linguistics Concentration 2 (Part 2) & $\mathrm{D}$ & 6 \\
\hline & Electives & $\mathrm{S}$ & 9 \\
\hline & Key competences & Key Competence Course & 3 \\
\hline & Computational Linguistics Team Laboratory & $\mathrm{S}$ & 6 \\
\hline & Total & & 30 \\
\hline \multirow{6}{*}{3} & Electives & $\mathrm{S}$ & 18 \\
\hline & Research seminar & $\mathrm{S}$ & 9 \\
\hline & Total & & 27 \\
\hline & Research colloquium & $\mathrm{S}$ & 3 \\
\hline & Master's thesis & & 30 \\
\hline & & & 33 \\
\hline
\end{tabular}

"The typical recommended course of study is as follows: in the first term, all students have to attend the module "Methods in Computational Linguistics" (9 credits) assessed by a written exam. The module introduces students to standard methodologies.

Based on the findings retrieved from http://www.ims.uni-stuttgart.de/studium/interessierte/ studiengaenge/bsc/index.en.html

The first semester includes a central course introducing and reviewing the most important concepts of Computational Linguistics. Standard methodologies are discussed and practised in hands-on exercises. A team laboratory in the second semester further develops the skills required in project (team) work both in research and in development. During the study, students are to choose two concentrations, one of which is usually the 
basis for the topic of Master's thesis. The following concentrations involve Computational Syntax und Semantics, Laboratory Phonology and Speech Processing, Statistical Natural Language Processing. During the programme, students are provided with the opportunity to spend their third semester abroad.

So, the programme is divided into depth and specialization courses. Students have to choose concentrations ( 24 credits) and electives (36 credits). In addition, they are to attend key competence ( 3 credits). The Master's thesis is equal to 30 credits. It is also recommended to rather choose lectures and overview / introductory courses in the beginning and seminars on specific topics in the later course of studies. The latter especially concerns those students who obtained Bachelor degrees different from Computational Linguistics / Natural Language Processing. The characteristics of the course details for a MSc in Computational Linguistics is given in Table 2.

It must be noted that research and development in Computational Linguistics and in Speech \& Language Technology require some key skills and competences for successfully working in project teams. The team laboratory is aimed at developing these skills and competences through practical team work on a specific project. Students are assessed based on the system implemented in the course and their project report.

During the MSc programme, students are given the opportunity to spend their third semester at a foreign university that is highly recommended: not only is this a valuable experience, it also offers the chance to make useful contacts that might help with the career choices later on.

As for electives, students may choose courses on specialized topics offered by the Institute of Natural Language Processing or from Master degree programmes offered by other university departments, in particular Computer Science and Electrical and (Theoretical) Linguistics. In addition, the Board of Admission may also allow other courses to be taken as electives; there is the possibility for students to use courses taken at a foreign university during studying abroad as electives.

Importantly, students must pass the Orientation Examination (Orientierungsprüfung) at latest at the beginning of the fourth semester to find out whether they have chosen the right career path or still need additional assistance.

Consequently, we can fully agree with the statement by H. Uszkoreit (2000), a scientific director at the German Research Center for Artificial Intelligence that "computational linguistics is a discipline between linguistics and computer science concerned with the computational aspects of the human language faculty, belongs to the cognitive sciences and overlaps with the field of artificial intelligence.

\section{CONCLUSIONS}

So, computational linguistics is rather a young scientific field that eventually causes numerous discussions among scholars all over the world trying to generate the most exact scope of its exercise. Indeed, German scholars view it as a cognitive science that attempts to most successfully apply the achievements of linguistics in practice. Based on the view, German universities develop curricula that encompass theoretical and practical aspects of computational linguistics to prepare modern specialists able to comprehend the complexity of the field and be willing to adapt to challenges of a globalized world.

The organization of computational linguists' professional training has been studied by the example of the University of Stuttgart. We have found out that those interested in pursuing their future career in computational linguistics may start from a BSc in Machine Language Processing and later proceed to a MSc in Computational Linguistics. The 
duration of the programmes is traditional - three and two years respectively. Their structure comprises obligatory and elective courses, including computer science, mathematics and linguistics. In addition, future specialists may develop key professional competences attending seminars and colloquiums, participating in research projects, etc. We are in particular impressed by the fact that the BSc students are not supposed to be fluent in programming languages as they may catch up during the course of the programme. The list of electives involves those subjects aimed at enhancing future specialists' skills in linguistics as well as computer science, yet they are entitled to suggest what they are interested in even if such courses are not included. Adhering to global trends in higher education, the University encourages the MSc students to study abroad (third semester), therefore, enhancing their mobility.

Ukrainian higher education universities have accumulated valuable experience in training future specialists in applied linguistics, too. Future applied linguists are provided with the latest achievements of linguistics, applied linguistics, computational linguistics as well other prominent linguistic branches. However, it is advisable, in our opinion, to draw a precise line between applied linguistics and computational linguistics, taking into account the peculiarities of the procedure at foreign universities. It is essential, as two fields being related still focus on different areas, which is why they should complement, yet not contradict each other or imply the same but in different ways.

Hence, rather perspective are further studies on the essence of the terms "applied linguistics" and "computational linguistics" based on the research findings of scholars all over the world.

\section{REFERENCES}

1. Davies, A., \& Elder, C. (2004). The Handbook of applied linguistics. Malden, MA; Oxford; Carlton, Victoria: Blackwell Publishing.

2. Duden. (2017). Computerlinguistik. Retrieved from http://www.duden.de/ rechtschreibung/Computerlinguistik.

3. Institut für Maschinelle Sprachverarbeitung. (2017). Bachelor of Science Maschinelle Sprachverarbeitung. Retrieved from http://www.ims.unistuttgart.de/studium/interessierte/studiengaenge/bsc/index.html.

4. Institut für Maschinelle Sprachverarbeitung. (2013). Computerlinguistik: Was ist das eigentlich? Retrieved from http://www.ims.uni-stuttgart.de/studium/interessierte/ leitfaden/.

5. Knapp, K. (2011). Angewandte Linguistik. Tübingen-Basel: Francke Verlag.

6. Königs, F. (1983). Normenaspekte im Fremdstrachenunterricht: ein Konzeptorientierter beitrag zur Erforschung des Fremdesprachenunterrichts. Tübingen: Gunter Narr Verlag.

7. Ludwig-Maximilians-Universität München. (2017). Computerlinguistik (Bachelor). Retrieved from https://www.uni-muenchen.de/studium/studienangebot/ studiengaenge/studienfaecher/computerl/bachelor/index.html.

8. Naves, T. (2008). Applied linguistics. What it is and the history of the discipline. Retrieved from http://diposit.ub.edu/dspace/bitstream/2445/4701/1/Naves2008A LDisciplinePartIonGrabe2002.pdf.

9. Semotiuk, O. (2017). Suchasni tekhnolohii linhvistychnykh doslidzhen. Lviv: Vydavnytstvo Lvivskoi Politekhniky. 
10. Selivanova, O. (2008). Suchasna linhvistyka: napriamy i problemy. Poltava: Narr Verlag.

12. Universität Heidelberg. (2017). Computerlinguistik. Retrieved from http://www. uni-heidelberg.de/studium/interesse/faecher/computerling_ba.html.

13. Universität Potsdam. (2011). Computerlinguistik. Ein-Fach-Bachelor. Retrieved from https://www.uni-potsdam.de/studium/studienangebot/bachelor/ein-fach-bachelor/ computerlinguistik.html.

14. Uszkoreit. H. (2000). What is computational linguistics? Retrieved from http://www.coli.uni-saarland.de/ hansu/what_is_cl.html.

15. Widdowson, H. (2000). The limitations of linguistics applied. Applied linguistics, 21 (1), 3-25. 